\title{
A EDUCAÇÃO FÍSICA E SEU PROCESSO DE FORMAÇÃO PARA A SAÚDE
}

\author{
EDUCACIÓN FÍSICA Y SU PROCESO DE FORMACIÓN SANITARIA
}

PHYSICAL EDUCATION AND ITS HEALTH TRAINING PROCESS

\author{
Viviany CAETANO FREIRE AGUIAR ${ }^{1}$ \\ Stela LOPES SOARES ${ }^{2}$ \\ Hamilton VALE LEITÃO ${ }^{3}$
}

RESUMO: A formação do profissional de educação física na saúde pública trata-se de uma das inquietações observadas no cotidiano do fazer da profissão de Educação Física, o que favorece as lacunas e fragilidades na atuação e difusão da profissão nos diferentes espaços. Para tanto, se tem como objetivo analisar o processo de formação do profissional de educação física para a saúde pública. Tendo como metodologia uma revisão integrativa de abordagem qualitativa. Após a seleção dos artigos e análise dos dados gerou-se um núcleo temático, a saber - Formação em saúde: os efeitos de sua tímida aparição nos cursos de graduação em educação física. Diante disto, conclui-se que a partir da literatura trazida, esses profissionais encontram uma base curricular fragilizada no que concerne às temáticas envolvendo o estudo da saúde, evidenciando um nível de complexidade na implicação desse processo de estudo. Desse modo, acredita que hoje, a Educação Física passou a ter aceitação no campo da saúde pública. Porém, se acredita que sua formação para atuar no sistema de saúde, ainda é vista de forma complexa e algumas das vezes até paradoxal.

PALAVRAS-CHAVE: Educação física. Formação profissional em saúde. SUS.

RESUMEN: La formación del profesional de la educación física en la salud pública es una de las preocupaciones observadas en la rutina de hacer la profesión de educación física, en la que favorece las lagunas y debilidades en el trabajo y la difusión de la profesión en los diferentes Espacios. Con este fin, el objetivo era analizar el proceso de formación del profesional de la educación física para la salud pública. Tener como metodología una revisión Integrativa del enfoque cualitativo. Tras la selección de artículos y análisis de datos, se generó un núcleo temático, a saber: la formación sanitaria: los efectos de su tímida aparición en los cursos de pregrado en educación física. En vista de ello, se concluye que, de la literatura llevada, estos profesionales se encuentran con una frágil base curricular sobre los temas que involucran el estudio de salud, evidenciando un nivel de complejidad en la implicación de este proceso de Estudio. De esta manera, cree que hoy en día, la educación física ha sido aceptada en el campo

${ }^{1}$ Centro Universitário INTA (UNINTA), Sobral, CE - Brasil. Profa. Esp. no curso de Educação Física - EAD. ORCID: <http://orcid.org/0000-0001-6982-3847>.E-mail: viviany_cfa@ hotmail.com

${ }^{2}$ Centro Universitário INTA (UNINTA), Sobral, CE - Brasil. Profa. Me. no Curso de Educação Física - EAD e do Curso de Fisioterapia do UNINTA e da Faculdade Alencarina (FAL). ORCID: <http://orcid.org/0000-00025792-4429>. E-mail: stelalopesoares@ hotmail.com

${ }^{3}$ Faculdade Alencarina - FAL e Centro Universitário INTA (UNINTA), Sobral, CE - Brasil. Prof. Dr. Diretor Geral; Diretor de Gestão Acadêmica e Administrativa da Educação à Distância. ORCID: <http://orcid.org/00000002-7343-7022>. E-mail: havaleitao@gmail.com 
de la salud pública. Sin embargo, todavía se cree que su formación para actuar en el sistema de salud, todavía se ve en una forma compleja y a veces incluso paradójica.

Palabras clave: educación física. Formación profesional en salud. Sus.

PALABRAS CLAVE: Educación física. Formación profesional en salud. SUS.

ABSTRACT: The training of the physical education professional in public health is one of the concerns observed in the routine of doing the physical education profession, in which favors the gaps and weaknesses in the work and dissemination of the profession in the different Spaces. To this end, the objective was to analyze the training process of the physical education professional for public health. Having as methodology an integrative review of qualitative approach. After the selection of articles and data analysis, a thematic nucleus was generated, namely: Health training: The effects of his shy appearance in undergraduate courses in physical education. In view of this, it is concluded that from the literature brought, these professionals find themselves with a fragile curricular basis regarding the themes involving the Health study, evidencing a level of complexity in the implication of this process of Study. In this way, he believes that today, physical education has been accepted in the field of public health. However, it is still believed that its formation to act in the health system, is still seen in a complex and sometimes even paradoxical way.

KEYWORDS: Physical Education. Professional training in health. SUS

\section{Introdução}

Uma das inquietações observadas no cotidiano do fazer da profissão de Educação Física, que favorece as lacunas e fragilidades na atuação e difusão da profissão nos diferentes espaços, é a formação do profissional de Educação Física na Saúde Pública.

A Educação Física sob sua origem no contexto brasileiro esteve estreitamente vinculada às instituições militares e à classe médica. Na década de 30, no Brasil, dentro de um contexto histórico e político mundial, o exército passou a ser a principal instituição a comandar um movimento em prol do "ideal" da Educação Física que se mesclava aos objetivos patrióticos e de preparação militar. O discurso eugênico logo cedeu lugar aos objetivos higiênicos e de prevenção de doenças. Estes sim, passíveis de serem trabalhados dentro de um contexto educacional (PCN, 1997).

Observa-se, dessa maneira, que a Educação Física, a partir de sua origem até a atualidade, é marcada por grandes influências que vão desde as práticas, militaristas, higienista, em que a preocupação fundamental eram a higiene e saúde, até mesmo a cultura corporal, que vai muito além do simples movimento corporal. Desse modo, a importância social da profissão 
e seu contexto histórico são responsáveis pela conquista de novos rumos nos quais estão sendo cada vez mais delineados (CHAGAS; GARCIA, 2011).

Desse modo, a área de Educação Física hoje contempla múltiplos conhecimentos produzidos e usufruídos pela sociedade a respeito do corpo e do movimento. Dentre eles, se consideram fundamentais as atividades culturais de movimento com finalidades de lazer, expressão de sentimentos, afetos e emoções, e com possibilidades de promoção, recuperação e manutenção da saúde (LIMA, 2013).

Até pouco tempo, e por um longo período, esta área foi vista apenas como uma disciplina curricular apresentada na Educação Básica e/ou ligada ao Treinamento Desportivo. Após alguns anos, pesquisas começaram a surgir no que diz respeito à atividade física. Nas quais pode ser constatada a importância que sua prática pode proporcionar a prevenção de doenças não transmissíveis, assim como, os problemas que a inatividade física pode provocar na saúde do indivíduo.

A partir dessas pesquisas, a Educação Física passou a ter aceitação no campo da saúde pública. Porém, se acredita que a formação do profissional de Educação Física, para atuar no sistema de saúde, ainda é vista de forma complexa e algumas das vezes até paradoxal.

De acordo com Benedetti et al. (2014) o setor da saúde exige uma formação integral, com saberes e competências com maior abrangência e diferentes possibilidades de intervenções em níveis institucionais, comunitários e políticos, considerando os princípios do Sistema Único de Saúde (SUS) e esta, ainda, não é a realidade da formação inicial dos professores de Educação Física. Dessa forma, o estudo tem como objetivo analisar o processo de formação do profissional de educação física para a saúde pública, mediante uma revisão integrativa.

\section{Metodologia}

A revisão integrativa inclui a análise de pesquisas relevantes que dão suporte para a tomada de decisão, possibilitando a síntese do estado do conhecimento de um determinado assunto, além de apontar lacunas do conhecimento que precisam ser preenchidas com a realização de novos estudos.

Os passos percorridos para operacionalização da pesquisa revisão foram: identificação do tema e seleção da questão de pesquisa, busca na literatura/estabelecimento dos critérios de inclusão, categorização dos estudos, avaliação dos estudos incluídos na revisão integrativa. 
Tendo por questão norteadora: como está a produção científica sobre a Educação Física e seu processo de formação para a saúde no nosso país?

Para a identificação do objeto de estudo na literatura, utilizou-se a pesquisa bibliográfica eletrônica nas seguintes bases de dados: Literatura Latino-Americana e do Caribe em Ciências da Saúde (LILACS), e portal Scientific Eletronic Library Online (SCIELO). Em que para LILACS o acesso foi via Biblioteca Virtual de Saúde (BVS).

A seleção dos artigos deu-se no mês de junho de 2018 a janeiro de 2019, tendo como estratégia de busca a combinação de três termos (Descritores em Ciências da Saúde - DeCS: educação física, formação profissional em saúde, e SUS) associados pelos operadores boolianos "and" e "or".

Definiu-se como critérios de inclusão os artigos publicados em periódicos indexados nas bases eletrônicas citadas acima, disponíveis em textos completos, escritos em português e que discutissem o objetivo da investigação. Como critério de exclusão, anulou-se as produções que se apresentarem repetidas ou as que não proporcionaram acesso ao trabalho completo para a análise mais aprofundada.

Para seleção dos artigos foram adotados os passos: leitura do título, seguida do resumo, o que resultou na seleção daqueles que possivelmente realizassem uma discussão ao objetivo proposto. Para organização dos dados elaborou-se uma tabela no software Microsoft Word, contendo título do artigo, ano de publicação, objetivo e considerações.

Para análise dos dados foi feita uma leitura flutuante das tabelas que ao final gerou um núcleo temático - Formação em saúde: os efeitos de sua tímida aparição nos cursos de graduação em educação física.

Quanto aos aspectos éticos, ressalta-se que foram respeitados os preceitos de autoria e referenciamento das publicações utilizadas. Como o referido estudo se configura de uma revisão integrativa de produções disponíveis e existentes sobre a temática, percebeu-se não ser necessário sua submissão a um Comitê de Ética e Pesquisa.

Realizando a filtragem por meio das palavras escolhidas, além dos critérios de inclusão, encontrou-se 100 artigos e após a leitura minuciosa dos mesmos, restaram apenas 10 artigos.

\section{Resultados e discussões}


É importante que seja destacado o grande valor do fomento em estudos que possibilitam a análise e reflexões de como se encontra o processo de formação e inserção da educação física na área da saúde.

Dos 10 artigos encontrados que atendiam ao objetivo do presente estudo, três deles abordam a atuação do profissional de educação física no âmbito da saúde pública, um apresenta tanto o processo de formação como atuação, e os demais procuram apresentar questões referentes à formação da educação física, com ênfase no ensino da saúde nos cursos de graduação de educação física. O ano de publicação variou entre os anos de 2010 a 2018.

Dos estudos encontrados percebe-se que possuem uma mesclagem de tipos de estudo, sendo provenientes tanto de pesquisas bibliográficas nas quais apresentou-se discussões e reflexões relacionadas ao objetivo proposto, assim como provenientes de pesquisas de campo, prevalecendo como instrumento de coleta de dados os questionários envolvendo o grau de competências de promoção da saúde entre os formandos dos cursos da área da saúde.

Neste sentido, apresenta-se um breve resumo dos trabalhos encontrados, os resultados da busca estão expressos no quadro a seguir:

Quadro 1 - Apresentação dos artigos segundo identificação, tipo do estudo, objetivos e considerações

\begin{tabular}{|c|c|c|c|}
\hline $\begin{array}{l}\text { Título do Artigo / } \\
\text { Ano de publicação }\end{array}$ & Tipo de Estudo & Objetivos & Considerações \\
\hline $\begin{array}{c}\text { Educação Física e } \\
\text { saúde: aproximações } \\
\text { com a “clínica } \\
\text { ampliada"/2013. }\end{array}$ & Ensaio & $\begin{array}{l}\text { Relacionar os aspectos da } \\
\text { educação física e saúde ao } \\
\text { referencial teórico-conceitual } \\
\text { e metodológico da Clínica } \\
\text { Ampliada. }\end{array}$ & $\begin{array}{c}\text { Assim, é premente refazermos } \\
\text { caminhos, aproximando formação } \\
\text { profissional e intervenção. }\end{array}$ \\
\hline $\begin{array}{l}\text { A Saúde Coletiva } \\
\text { nos Cursos de } \\
\text { Graduação em } \\
\text { Educação } \\
\text { Física/2010. }\end{array}$ & Qualitativo & $\begin{array}{l}\text { Ajudar na compreensão de } \\
\text { como está sendo realizado o } \\
\text { ensino de Saúde Coletiva nos } \\
\text { cursos de graduação de } \\
\text { educação física em duas } \\
\text { importantes instituições } \\
\text { públicas de ensino do estado } \\
\text { de São Paulo. }\end{array}$ & $\begin{array}{c}\text { Concluiu-se que dentro das } \\
\text { universidades estaduais paulistas, } \\
\text { USP e Unicamp, as disciplinas dos } \\
\text { cursos de educação física } \\
\text { estudadas neste artigo não são } \\
\text { suficientes para oferecer uma } \\
\text { formação densa em Saúde } \\
\text { Coletiva. }\end{array}$ \\
\hline $\begin{array}{l}\text { Educação Física na } \\
\text { saúde pública: } \\
\text { Revisão } \\
\text { Sistemática/2015. }\end{array}$ & $\begin{array}{c}\text { Estudo } \\
\text { bibliográfico }\end{array}$ & $\begin{array}{c}\text { Propor uma reflexão sobre a } \\
\text { produção acadêmica } \\
\text { brasileira entre os anos } 2000 \\
\text { e } 2012 \text {, na temática } \\
\text { Educação Física na Saúde } \\
\text { Pública. }\end{array}$ & $\begin{array}{l}\text { A inserção do professor de } \\
\text { Educação Física tem dado sinais de } \\
\text { tímida ampliação da atuação } \\
\text { formalizada através de concurso } \\
\text { público, o que é um desafio e só } \\
\text { será possível a partir da } \\
\text { demonstração que este profissional }\end{array}$ \\
\hline
\end{tabular}




\begin{tabular}{|c|c|c|c|}
\hline & & & $\begin{array}{l}\text { tem a capacidade e as condições } \\
\text { necessárias e legítimas para o } \\
\text { desafio de (re)construção do } \\
\text { Sistema Único de Saúde brasileiro. }\end{array}$ \\
\hline $\begin{array}{l}\text { A formação do } \\
\text { profissional de } \\
\text { Educação Física e o } \\
\text { Sistema Único de } \\
\text { Saúde/2017. }\end{array}$ & Qualitativo & $\begin{array}{l}\text { Identificar o conhecimento } \\
\text { dos estudantes de Educação } \\
\text { Física de uma Instituição de } \\
\text { Ensino Superior de Santa } \\
\text { Catarina sobre a atuação } \\
\text { deste profissional na Atenção } \\
\text { Básica do Sistema Único de } \\
\text { Saúde. }\end{array}$ & $\begin{array}{c}\text { A formação superior dos cursos da } \\
\text { saúde, e no caso desse estudo da } \\
\text { Educação Física, precisam } \\
\text { direcionar os estudantes para que } \\
\text { melhor compreendam esse cenário } \\
\text { de prática, a fim de qualificar sua } \\
\text { formação e o trabalho desse futuro } \\
\text { profissional. }\end{array}$ \\
\hline $\begin{array}{c}\text { Formação em } \\
\text { Educação Física: } \\
\text { experiências de } \\
\text { integração ensino- } \\
\text { serviço na atenção } \\
\text { básica em } \\
\text { saúde/2016. }\end{array}$ & Qualitativo & $\begin{array}{c}\text { Problematizar sobre a } \\
\text { formação em saúde, partindo } \\
\text { de experiências de um grupo } \\
\text { de estudantes de Educação } \\
\text { Física no PET-Saúde USP } \\
\text { Capital. }\end{array}$ & $\begin{array}{c}\text { A prática pedagógica de } \\
\text { integração ensino-serviço no PET- }- \\
\text { Saúde é um potente ingrediente e } \\
\text { é estratégica para a formação de } \\
\text { futuros profissionais que, ao } \\
\text { menos, precisam ter opção do } \\
\text { contexto sócio histórico e político } \\
\text { em saúde para melhor se situarem } \\
\text { diante da conjuntura nacional em } \\
\text { consonância com o SUS. }\end{array}$ \\
\hline $\begin{array}{l}\text { Formação e } \\
\text { intervenção } \\
\text { profissional em } \\
\text { saúde pública: } \\
\text { percepções de } \\
\text { profissionais de } \\
\text { educação } \\
\text { física/2017. }\end{array}$ & Exploratório & $\begin{array}{l}\text { Analisar as percepções de } \\
\text { profissionais de Educação } \\
\text { Física sobre os processos de } \\
\text { formação e seus reflexos na } \\
\text { atuação em serviços da } \\
\text { Saúde Pública em } \\
\text { Goiânia/GO. }\end{array}$ & $\begin{array}{l}\text { Os Profissionais de Educação } \\
\text { Física perceberam e apontaram as } \\
\text { fragilidades na formação } \\
\text { universitária quando relacionada à } \\
\text { atuação profissional, } \\
\text { especialmente por não } \\
\text { problematizar o trabalho na } \\
\text { perspectiva da Saúde Pública. }\end{array}$ \\
\hline $\begin{array}{l}\text { Competências para } \\
\text { promoção da saúde } \\
\text { em formandos dos } \\
\text { cursos da área da } \\
\text { saúde/2017. }\end{array}$ & $\begin{array}{c}\text { Observacional, } \\
\text { transversal e } \\
\text { quantitativo }\end{array}$ & $\begin{array}{l}\text { Avaliar o grau de } \\
\text { competências de promoção } \\
\text { da saúde dentre os } \\
\text { formandos dos cursos da } \\
\text { área da saúde. }\end{array}$ & $\begin{array}{l}\text { O estudo convergiu para o } \\
\text { desenvolvimento aquém, durante } \\
\text { os cursos de graduação, das } \\
\text { competências para realização das } \\
\text { atividades de promoção da saúde. }\end{array}$ \\
\hline $\begin{array}{c}\text { Políticas de } \\
\text { formação em } \\
\text { educação física e } \\
\text { saúde coletiva/2012. }\end{array}$ & Ensaio & $\begin{array}{l}\text { Analisar os processos de } \\
\text { composição e articulação } \\
\text { entre ensino, serviço e } \\
\text { comunidade com vistas a } \\
\text { constituir uma rede de } \\
\text { saberes e práticas que } \\
\text { responda aos desafios da } \\
\text { formação em saúde } \\
\text { comprometida com a defesa } \\
\text { e consolidação do Sistema } \\
\text { Único de Saúde. }\end{array}$ & $\begin{array}{c}\text { As experiências acadêmicas no Pró- } \\
\text { Saúde e no PET-Saúde e a atuação } \\
\text { profissional na ESF e no Nasf } \\
\text { podem ser interessantes para } \\
\text { reorientar as ações em saúde. }\end{array}$ \\
\hline
\end{tabular}




\begin{tabular}{|c|c|c|c|}
\hline $\begin{array}{c}\text { Atuação do } \\
\text { profissional de } \\
\text { Educação Física no } \\
\text { Sistema Único de } \\
\text { Saúde: uma análise a } \\
\text { partir da Política } \\
\text { Nacional de } \\
\text { Promoção da Saúde } \\
\text { e das Diretrizes do } \\
\text { Núcleo de Apoio à } \\
\text { Saúde da Família - } \\
\text { NASF/2012. }\end{array}$ & $\begin{array}{c}\text { Estudo } \\
\text { bibliográfico }\end{array}$ & $\begin{array}{l}\text { Analisar e discutir a atuação } \\
\text { do profissional da educação } \\
\text { física no SUS sob a } \\
\text { perspectiva da promoção da } \\
\text { saúde como "um processo de } \\
\text { capacitação da comunidade } \\
\text { para melhorar a sua } \\
\text { qualidade de vida". }\end{array}$ & $\begin{array}{l}\text { A proposta de atuação do } \\
\text { profissional de educação física no } \\
\text { SUS por meio do NASF foi } \\
\text { elaborada a partir dos princípios } \\
\text { da Política Nacional de Promoção } \\
\text { da Saúde (PNPS), com base no } \\
\text { eixo de práticas corporais e } \\
\text { atividade física (PCAF) da PNPS } \\
\text { que possui a Atenção Básica como } \\
\text { principal foco de atuação, } \\
\text { buscando a consolidação e } \\
\text { qualificação da ESF como centro } \\
\text { ordenador das redes de atenção à } \\
\text { saúde no SUS. }\end{array}$ \\
\hline $\begin{array}{c}\text { A atuação da } \\
\text { educação física no } \\
\text { âmbito da saúde } \\
\text { pública - Uma } \\
\text { revisão } \\
\text { sistemática/2015. }\end{array}$ & $\begin{array}{c}\text { Estudo } \\
\text { bibliográfico }\end{array}$ & $\begin{array}{l}\text { Mostrar a importância da } \\
\text { inserção do profissional de } \\
\text { educação física nas ações } \\
\text { desenvolvidas no âmbito da } \\
\text { saúde pública. }\end{array}$ & $\begin{array}{l}\text { Diante das múltiplas funções que tal } \\
\text { profissional precisa desempenhar na } \\
\text { saúde pública, o profissional de } \\
\text { Educação Física necessita de uma } \\
\text { formação continuada, para que } \\
\text { adquire os conhecimentos } \\
\text { necessários ao desenvolvimento de } \\
\text { uma melhor ação, capaz de } \\
\text { contribuir para a melhoria da } \\
\text { qualidade da população assistida. }\end{array}$ \\
\hline
\end{tabular}

Fonte: Autoria própria. 2019.

\section{Formação em saúde: os efeitos de sua tímida aparição nos cursos de graduação em educação física}

A educação física nos últimos anos tem evidenciado possibilidades de ampliação do conhecimento no campo da saúde. As diretrizes curriculares anteveem que o ingresso do curso possa ser responsável pela promoção, prevenção e proteção da saúde dos indivíduos. Para isso, é necessário que os cursos possam ofertar uma base teórica de forma que substancie a qualidade de formação destes profissionais.

De acordo com Freitas (2013), transformações exigem conhecimento teórico e prático que norteie o trabalho profissional, com base nos princípios do SUS; uma concepção de saúde que contemple a complexidade do campo; efetiva aproximação entre ensino e serviço; e responda às necessidades de saúde da população.

A graduação na área da saúde, da qual a educação física é parte e exemplo, não prioriza a integração entre ensino e trabalho e também não está voltada para uma formação teóricoconceitual e metodológica que potencialize competências para a integralidade, em que se inclui 
o enfretamento das necessidades de saúde da população e de desenvolvimento do sistema de saúde (FREITAS,2013).

É necessário que seja legitimado um referencial teórico-metodológico capaz de organizar e planejar o trabalho em saúde para que a educação física seja avaliada e ressignificada.

Estudos sobre o SUS e a Saúde Coletiva ocupam lugar de pouco prestígio nas grades curriculares. A demanda crescente por profissionais aptos ao trabalho no SUS não efetivou uma formação interdisciplinar e voltada às necessidades de saúde (PASQUIM, 2010).

O cuidado na formação profissional para o trabalho em saúde é primordial para uma reorientação ao sistema de saúde. Diante disto, percebe-se a necessidade da qualificação tanto na academia quanto no campo de atuação dos profissionais de saúde como estratégia frente às mudanças que ocorrem no setor saúde.

Pasquim (2010), afirma que o objetivo de aproximação da área da saúde pública/saúde coletiva requer da Educação Física pensar sobre dois grandes problemas a serem enfrentados: a quebra da hegemonia instalada e fortalecida pela produção científica e pelas formas de atuação do profissional de Educação Física; a reorientação do processo de formação acadêmica, historicamente pouco preocupado com a consideração dos condicionantes globais da vida humana, fatores intervenientes do processo saúde-doença e, ainda menos, com o sistema público de saúde.

Estas reflexões têm sido significativas para o debate a respeito das relações existentes entre a Educação Física e a saúde, uma vez que estes trabalhos têm contribuído para ampliar o enfoque, demonstrando que o simples efeito orgânico da atividade física é insuficiente para promover saúde quando se pensa nas determinações sociais do processo saúde-doença (PASQUIM, 2010).

Nessa perspectiva, a formação superior dos cursos de saúde, mais especificamente da educação física, que é o enfoque deste estudo, necessita de um direcionamento maior ao estudante, com vista de uma maior compreensão sobre o cenário de prática para a melhor qualificar sua formação e o trabalho deste futuro profissional.

De acordo com uma pesquisa realizada no estudo de Manske (2017), percebeu-se que os estudantes investigados disseram pouco ou nada conhecer sobre o SUS e as estruturas que organizam seu funcionamento, o que indica, a partir de excertos de suas falas, que não saberiam como atuar nesse espaço profissional. Tal constatação reverbera não apenas numa inadequação da formação profissional para esse campo, como também e principalmente, corrobora para que o funcionamento dos princípios que norteiam o SUS sejam desqualificados, implicando em 
maiores dificuldades de avanços na Saúde Pública brasileira por parte dos profissionais recém egressos.

Embora aconteça muitas fragilidades no processo de formação, medidas de formação profissional e universitária estão acontecendo com o intuito de atender a demanda e especialmente os princípios do SUS. Pode-se mencionar que os indicativos desse processo, encontram-se o PET-saúde e as Residências Multiprofissionais, além disso, outra possibilidade de atuação que pode ser apontada é o estágio de vivência no SUS, o programa VER-SUS, em que acadêmicos fazem imersão, embora curta, nesse universo que futuramente poderão atuar.

Embora ainda restrito a pequena parcela de estudantes e instituições, o PET-Saúde, de um lado, é uma estratégia em potencial para responder às proposições do Ministério da Saúde com relação ao SUS e, de outro, supre a necessidade de aproximar ensino serviço e enfrentar os impasses da distância entre a universidade e a sociedade. É uma iniciativa recente e que efetivamente tem aberto e ampliado as relações e os diálogos com o SUS, principalmente durante a formação, pois se trata de um período crítico na vida do estudante (PRADO, 2016).

Pode-se vislumbrar que ainda há uma tímida inserção de estudantes e profissionais de educação física no Sistema Único de Saúde, principalmente comparado com as demais áreas da saúde. Porém podem ser observados interesses em estudos e pesquisas na área por parte de pesquisadores, em participar em assuntos no campo da Saúde Pública e Coletiva e sua intervenção orientada pelos princípios do SUS, deixando a compreender que esta área tem a que ser muito conquistado e trabalhado no processo de formação.

\section{Síntese do conhecimento}

Os estudos sobre a educação física e saúde tem se alavancado nos últimos anos. Pesquisadores e grupos de pesquisa estão cada vez mais interessados em estudar sobre esta área de atuação.

A partir da pesquisa nesse cenário, evidenciam-se algumas fragilidades. Para que a educação física se fortaleça no contexto da saúde pública, é necessário que os cursos de graduação compreendam e valorizem a necessidade de abordar a área nas disciplinas curriculares.

A análise de todos os artigos permitiu perceber a existência de um enfrentamento de dificuldades pode ser visualizada em alguns níveis de complexidade. A atenção básica considera a atuação do profissional de educação física importantíssimo aliado à ESF e NASF, 
em vista de serem grandes responsáveis na prevenção e promoção da saúde por meio da prática da atividade física nos grupos e comunidades, porém na visão de gestores e demais profissionais, a educação física ainda é limitada à intervenções na saúde pública, pois acreditam que a referida área é totalmente voltada ao discurso biologicista e fisiológico, ou seja, ainda distante do discurso biomédico.

No que tange à formação da saúde, observou-se uma tímida aparição das disciplinas curriculares com maiores direcionamentos à saúde coletiva, saúde pública ou até ao Sistema Único de Saúde, o que, de acordo com os estudos, resulta em uma base bastante fragmentada da saúde pública nos cursos de graduação.

Identificou-se em alguns estudos que hoje programas como PET e Residência tem surgido dentro da formação, porém sua inserção ainda é pouco vista na maioria das universidades que ofertam o curso.

O conhecimento do perfil dos futuros profissionais de Educação Física na área da saúde pode revelar questões referentes à sua identificação com o trabalho e à preparação para a atuação nos serviços de saúde, além de contribuir para o aperfeiçoamento, tanto dos serviços quanto das instituições formadoras.

É importante destacar que a base para a organização do processo de formação, bem como a análise e avaliação do currículo, necessita da determinação desse perfil profissional. Sendo assim, torna-se fundamental que as instituições formadoras possam apresentar um trabalho de desenvolvimento e reestruturação permanentemente dos perfis e carreiras profissionais sob sua responsabilidade.

Diante disto, a interface entre formação e atuação profissional, deve estar cada vez mais próxima, para que assim, estas possam contribuir mutuamente para alcançar o objetivo comum de tornar a realidade do trabalho em saúde mais próxima dos princípios do SUS.

Quando este estudo foi inicialmente idealizado havia o interesse em se estudar a temática Educação Física e Formação para saúde. A ideia original encaminha-se para o estudo de possibilidades atuais de formação da Educação Física.

Diante dos achados, acreditamos que se faz necessário discutir currículo e ensino na Universidade para formação de discentes, com ênfase nas disciplinas e projetos que focalizem as concepções de saúde.

\section{Considerações finais}


As inquietações sobre o objeto de estudo que levou o aprofundamento da temática tendo como método a revisão integrativa, permitiu contribuir para demonstrar como se encontram os caminhos de formação do profissional de educação física na saúde pública. Percebeu-se a partir da literatura trazida que esses profissionais possuem uma base curricular fragilizada no que concerne às temáticas envolvendo o estudo da saúde, evidenciando um nível de complexidade na implicação desse processo de estudo.

A formação do profissional de saúde, no nosso caso, o do profissional de Educação Física é norteada pelos Projetos Pedagógicos dos Cursos, contudo é imprescindível que o que foi planejado, aconteça para que os objetivos traçados sejam atingidos. Os currículos, além de estarem alinhados as propostas norteadoras do ensino em saúde, devem também atender aos anseios da comunidade acadêmica pois, são eles que (re)constroem a formação dos cursos no Brasil.

As literaturas analisadas contribuíram para compreender a percepção do profissional de educação física frente às influências da formação inicial e da realizada nos lócus de atuação profissional em serviço de Saúde Pública, trazendo reflexões sobre as influências desses processos na atuação profissional.

Dessa maneira, percebe-se alguns contrapontos no que diz respeito à organização de atividades do profissional de Educação Física neste campo de atuação, principalmente no tocante a formação inicial e continuada voltada para esta área.

Diante disto, as instituições de ensino superior necessitam apresentar um maior embasamento nas disciplinas que trabalhem o estudo da saúde pública, políticas públicas do trabalho multiprofissional, políticas de promoção da saúde, saúde coletiva, com vista em integrar o maior conhecimento possível aos egressos que possam futuramente vir atuar neste campo de trabalho.

\section{REFERÊNCIAS}

\section{BENEDETTI, Tânia R. Bertoldo et al. A formação do profissional de Educação Física} para o setor saúde. Florianópolis: Postmix, 2014. 146 p.

BRASIL. Parâmetros curriculares nacionais: Educação física / Secretaria de Educação Fundamental. - Brasília: MEC/SEF, 1997.

DA SILVA, Jordan Medeiros; JÚNIOR, José Maurício de Figueiredo. A atuação da educação física no âmbito da saúde pública - Uma revisão sistemática. REBES (Pombal - PB, Brasil), 
v. 5, n. 1, p. 75-86 jan./mar., 2015 ISSN - 2358-2391. Disponível em:

https://www.gvaa.com.br/revista/index.php/REBES/article/view/3208/2703.

DE CARVALHO, Vanessa Lôbo et al. Competências para promoção da saúde em formandos dos cursos da área da saúde. Rev enferm UFPE on line. Recife, v. 11, n. 8, p. 3269-78, ago. 2017.

FRAGA, Alex Branco; CARVALHO, Yara Maria de; GOMES, Ivan Marcelo. Políticas de formação em educação física e saúde coletiva. Trab. educ. saúde, Rio de Janeiro, v. 10, n. 3, p. 367-386, nov. 2012. Disponível em:

http://www.scielo.br/scielo.php?script=sci_arttext\&pid=S1981-

$77462012000300002 \& \operatorname{lng}=e n \& n r m=$ iso. Acesso em: 09 out. 2018.

FREITAS, Fabiana Fernandes de; CARVALHO, Yara Maria de; MENDES, Valéria Monteiro. Educação física e saúde: aproximações com a "Clínica Ampliada". Rev. Bras. Ciênc. Esporte [online]. 2013, vol. 35, n. 3, p. 639-656. ISSN 2179-3255. DOI: http://dx.doi.org/10.1590/S0101-32892013000300009.

LIMA, Rubens Rodrigues. Para compreender a história da educação física. Educação e Fronteiras, Dourados, v. 2, n. 5, p. p. 149-159, mar. 2013. Disponível em: http://ojs.ufgd.edu.br/index.php/educacao/article/view/2241/1277. Acesso em: 27 set. 2018.

MANSKE, George Saliba; DE OLIVEIRA, Daniel. A formação do profissional de Educação Física e o sistema único de saúde. Motrivivência, Florianópolis, v. 29, n. 52, p. 191-210, set. 2017. ISSN 2175-8042. Disponível em:

https://periodicos.ufsc.br/index.php/motrivivencia/article/view/2175-8042.2017v29n52p191. Acesso em: 09 out. 2018. DOI: https://doi.org/10.5007/2175-8042.2017v29n52p191.

NEVES, Ricardo Lira de Rezende; ANTUNES, Priscilla de Cesaro; BAPTISTA, Tadeu João Ribeiro; ASSUMPÇÃO, Luís Otávio Teles. Educação física na saúde pública: revisão sistemática - R. bras. Ci. e Mov. v. 23, n. 2 p. 163-177, dez. 2015 Disponível em: https://portalrevistas.ucb.br/index.php/RBCM/article/view/5197. Acesso em: 09 out. 2018. DOI: http://dx.doi.org/10.18511/0103-1716/rbcm.v23n2p163-177.

NEVES, Ricardo Lira de Rezende; ASSUMPÇÃO, Luis Otávio Teles. Formação e intervenção profissional em saúde pública: percepções de profissionais de educação física. Movimento (ESEFID/UFRGS), Porto Alegre, p. 201-212, mar. 2017. ISSN 19828918. Disponível em: https://seer.ufrgs.br/Movimento/article/view/65321. Acesso em: 09 out. 2018. DOI: https://doi.org/10.22456/1982-8918.65321.

PASQUIM, Heitor Martins. A saúde coletiva nos cursos de graduação em Educação Física. Saúde soc., São Paulo, v. 19, n. 1, p. 193-200, mar. 2010. Disponível em: http://www.scielo.br/scielo.php?script=sci_arttext\&pid=S0104$12902010000100016 \& \operatorname{lng}=$ en\&nrm=iso. Acesso em: 09 out. 2018. DOI: http://dx.doi.org/10.1590/S0104-12902010000100016.

PRADO, Alessandro Rovigatti do; CARVALHO, Yara Maria de. Formação em educação física: experiências de integração ensino-serviço na atenção básica em saúde. Movimento, Porto Alegre, v. 22, n. 2, 635-646, abr./jun. de 2016. 
SCABAR, Thaís Guerreiro; PELICIONI, Andrea Focesi; PELICIONI, Maria Cecília Focesi. Atuação do profissional de Educação Física no Sistema Único de Saúde: uma análise a partir da Política Nacional de Promoção da Saúde e das Diretrizes do Núcleo de Apoio à Saúde da Família - NASF. J. Health Sci. Inst. 2012.

\section{Como referenciar este artigo}

CAETANO FREIRE AGUIAR, Viviany; LOPES SOARES, Stela; VALE LEITÃO, Hamilton. A Educação Física e seu processo de formação para a saúde. Revista on line de Política e Gestão Educacional, Araraquara, v. 23, n. 2, p. 428-440, maio/ago., 2019. E-ISSN:1519-9029. DOI: $10.22633 /$ rpge.v23i2.12649

Submetido em: 10/03/2019

Revisões requeridas: 15/04/2019

Aprovado em: 06/05/2019

Publicado em: 09/06/2019 